\title{
Regional variability in population acute myocardial infarction cumulative incidence and mortality rates in Spain 1997 and 1998
}

\author{
Jaume Marrugat, Roberto Elosua, Elena Aldasoro, María José Tormo, Hermelinda \\ Vanaclocha, Antonio Segura, Miquel Fiol, Concepción Moreno-Iribas, Gloria Pérez, \\ José María Arteagoitia, Lluis Cirera, Adolfo Cabadés, Gema Vega, José Ignacio \\ Ayestarán, Vega García, Iraida Hurtado-de-Saracho, José García, Oscar Zurriaga, Javier \\ Muñiz, Joan Sala
}

\begin{abstract}
Background: Myocardial infarction (MI) incidence and mortality display a high geographic variation. Aims: The objective of the present study was to analyze MI mortality, cumulative incidence rate variability in seven regions of Spain from 1997 to 1998. Methods and Results: Standardized methods were used to identify, find, register, and classify MI cases that were classified as definite, possible, insufficient-dataMI, and non-MI. The total population of the seven monitored regions was 7,364,682 inhabitants. Of the 11,256 cases fulfilling eligibility criteria to investigate, 10,660 were selected to calculate MI rates: 6554 (61.5\%)non-fatal definite MI, 1179 (11.1\%)fatal definite MI, 1859 (17.4\%)fatal possible MI, 1068 (10.0\%)fatal cases with insufficient data. The IBERICA 25-74 years agestandardized cumulative incidence rates for men and women, were 207 (range: 175-252) and 45 (range: 36-65) per 100,000, respectively. The age-standardized mortality rates for men and women, were 73 (range: 62-94) and 20 (range: 13-29) per 100,000, respectively. Age-standardized case-fatality was 31.4 and $24.2 \%$ in men aged $25-74$ and 35-64 years, respectively, and 32.7 and 27.0\%, respectively, in women. Conclusions: MI cumulative incidence and mortality rates are low compared with other industrialized countries but, vary considerably among regions in a Mediterranean country like Spain.
\end{abstract}

Key wods

Coronary disease, Cumulative incidence rate, Mortality rate, Myocardial infarction, Registry

\section{Introduction}

Although, coronary heart disease (CHD) mortality rates appear to have decreased and stabilized in the last 30 years in Spain [1,2], CHD is expected to continue to be the leading cause of death in Spain, as in other industrialized countries, in the next two decades [3]. However, low event rates are observed in Spain as compared with other industrialized countries $[4,5]$.

There are some studies showing a considerable differences of MI event rates among countries [6, 7], which arises interesting issues on the determinants of such a variability, taking into account that the low incidence rates in southern Europe Mediterranean countries contrasts with the high cardiovascular risk factor prevalence observed [8-14]. MI incidence data were scarce in Spain owing to the difficulty of recording out-of-hospital fatal MI cases, and the only population data came from two neighboring areas in the north-eastern part of the country $[4,5]$.

The objective of the present study was to determine and compare MI event rates in a prospective population registry in seven Spanish regions in 1997-1998.

\section{Methods}

The Investigacion Búsqueda Específica y Registro de Isquemia Coronaria Aguda (IBERICA) study was designed to prospectively monitor and compare the MI cumulative incidence and mortality rates and 28-day case-fatality observed in seven regions of Spain (i.e. Castilla-La Mancha, Gerona, Majorca, Murcia, Navarra, Basque Country and Valencia) among residents aged 25-74, in 1997 and 1998. 
Identical methods have been used in all areas to detect MI events, and to record demographic and clinical characteristics, and complications including death occurred within 28 days of onset of symptoms.

\section{Subjects}

The study was designed as a population registry of patients aged 25-74 years with a MI in the seven regions of the IBERICA study. The reference population of the participating areas included in average $3,638,940$ men and 3,725,742 women according to official projections for the 1997-1998 period [15]. There were 99 hospitals of all levels operating in these areas.

\section{Case-finding procedures and sources}

Case-finding procedures for hospitalized patients included: (1) A "hot pursuit" during admission was used in all hospitals with a reference coronary care or intensive care unit (CCU); (2) to identify patients not admitted to a CCU, all medical records of patients with a discharge diagnosis code 410-414 of the international classification of diseases 9th revision (ICD-9) were reviewed in all hospitals of the area ('cold pursuit'); (3) the medical records of those patients with the diagnosis ICD-9 410-414 in emergency room of all hospitals were also reviewed by cold pursuit; and (4) the records of secondary medically attended transportation were also screened to identify possible MI cases referred to medical centers out of the area.

To identify out-of-hospital MI fatal cases all the death certificates containing suggestive ICD-9 410 414 codes were investigated by reviewing medical records, interviewing physicians who signed the selected death certificate or assigned general practitioner, and relatives or witnesses when deemed necessary by using a standardized questionnaire.

\section{Event classification}

Each event was classified according to the MONICA algorithm [16], which takes into account the type of symptoms, electrocardiographic (ECG) findings, cardiac enzyme values, and history of ischaemic heart disease and necropsy interpretation in fatal cases. Each event was classified into one of the following diagnostic categories:

(a) Non-fatal Definite MI patients with serial ECGs showing either: (1) progression from no Q wave to Q wave, or (2) ST-segment depression, developing ST segment elevation or progressive T-wave inversion, or (3) persistent ST-segment elevation with progressive T-wave inversion, or (4) patients with other ECG characteristics and cardiac enzyme levels at least twice the normal limit (creatinphosphokinase, and creatin-phosphokinase-MB fraction), either with typical symptoms (chest pain lasting at least $20 \mathrm{~min}$ which cannot be definitely attributable to non-coronary heart disease pathologies) or non-typical symptoms. ECG findings were analyzed by trained medical, but noncardiologist, investigators using standardized criteria.

(b) Fatal Definite MI if they satisfied non-fatal definite criteria or if autopsy showed recent myocardial infarction or coronary thrombosis.

(c) Non-fatal Possible MI events with typical symptoms although without the electrocardiographic or enzymatic criteria to be defined as definite MI, but no other definite cause of death.

(d) Fatal Possible MI involved suggestive terminal symptoms, or a CHD history in the absence of an autopsy, or autopsy findings of chronic occlusive CHD or old infarction but no other pathological finding suggestive of a fatal disease.

(e) Fatal Insufficient data events was used when a patient had no record of suggestive symptoms, or previous CHD, or an autopsy, and were therefore unclassifiable.

(f) No myocardial infarction or coronary death when another cause of death was implied by the clinical history or at autopsy. Also 28-day cardiac arrest survivors from CHD without criteria to be defined as definite or possible, were included in this category.

Rates for fatal and non-fatal definite and fatal possible MI are presented alone and together with insufficient-data fatal cases. 


\section{Quality control}

All field investigators were trained together in a 2-day course before starting the study. Agreement in case classification among them was assessed by a set of cases that had to be independently categorized and included some duplicate cases. All investigators had to reach an intraindividual agreement and an agreement with the standard classification provided by the coordinating center (i.e. Multiple Kappa statistics value $\geq 0.94$ ) to obtain proper accreditation.

Moreover, all registered events were blindly reclassified into one of the above-mentioned categories in the coordinating center, and all discrepancies were discussed with field and local investigators until a consensus category was reached.

The number of the investigated deaths in the study was also compared with the number of coronary heart disease deaths in official statistics of each area. The study-to-official rate (i.e. coverage) was calculated [17]. Results ranged from 0.95 to 1.23 , but all except one had values $>1$. Data were entered in an ad hoc computer program which automatically warned against out-of-range values and checked internal consistency of individual information.

\section{Statistical analysis}

Rates were standardized by age using the world standard population weights for the 25-74 and 35-64 age intervals [16]: 25-34 (14/50), 35-44 (12/50), 45-54 (11/50), 55-64 (8/50), 65-74 (5/50) in order to facilitate comparability with other registers. Case fatality at 28 days was standardized by age for the $35-$ 64 age interval using the MONICA data center weights: 35-44 (1/11), 45-54 (3/11) and 55-64 (7/11). For the 25-74 age interval the following weights were used: $25-34$ (1/100); 35-44 (7/100); 45-54 (16/100); 55-64 (26/100); 65-74 (50/100).

Aggregated data for 1997-1998 are presented in tables and figures broken down by area, decades of age, and sex. Crude and age-standardized cumulative incidence and mortality rates are presented per 100,000 inhabitants. The study includes 1997-1998 data for all centers excepted Valencia which includes only 1998 data. Standardized rates are presented with 95\% confidence intervals calculated according to the normal approximation of the Poisson distribution. Standardized mortality and cumulative incidence ratios with $95 \%$ confidence intervals were used to compare each participant region event rate with the IBERICA average in the 25-74 years population.

\section{Results}

Between 1997 and 1998, 11,256 cases fulfilling eligibility criteria were investigated. The distribution by diagnostic category and sex is shown in Table 1 . Rates were calculated using 10,660 cases (8412 men, 2248 women) with non-fatal and fatal definite MI, fatal possible MI, and fatal cases with insufficient data. The proportion of insufficient data cases in all regions was in average $10.0 \%$ of total cases, and $26.0 \%$ of fatal cases.

Table 1. Distribution of investigated and included cases by diagnostic categories and sex. Aggregated data from 1997 to 1998 in the IBERICA Study (Spain). Age groups 25-74 years

\begin{tabular}{|c|c|c|c|c|c|c|}
\hline Diagnostic categories & \multicolumn{2}{|c|}{ Investigated cases } & \multicolumn{2}{|c|}{ Investigated fatal cases } & \multicolumn{2}{|c|}{ Included cases } \\
\hline Definite MI & $6195(55.0)$ & $1538(13.7)$ & 893 (20.6) & $286(6.6)$ & $6195(58.1)$ & $1538(14.4)$ \\
\hline Not an $\mathrm{MI}^{\mathrm{a}}$ & $263(2.3)$ & $85(0.7)$ & $162(3.7)$ & $58(1.3)$ & - & - \\
\hline Total & $8863(78.7)$ & $2393(21.3)$ & $3272(75.6)$ & $1054(24.4)$ & $8412(78.9)$ & $2248(21.1)$ \\
\hline
\end{tabular}

MI: Myocardial infarction.

${ }^{a}$ After investigating the medical records and interviewing the physician who signed the death certificate and/or the patient relatives 
The 1997-1998 crude and age-standardized cumulative incidence and mortality annual rates per 100,000 inhabitants by age groups, for all definite and fatal possible MI, and with the fatal insufficient data category added are presented in Tables 2 and 3, for men and women, respectively. Age-standardized cumulative incidence, for the 35-64 and 25-74 years population, were 206 and 207 in men, and 32 and 45 in women, respectively (Tables 2 and 3). Rates increased smoothly with age in men, while a sharp increase appeared in women after the age of 55. Age-adjusted cumulative incidence rates for the 25-74 years population are presented by sex and region in Figure 1. Two regions had a standardized incidence rates significantly over the average, and three regions had rates under the average in men. One was over and two under the IBERICA average in women (Figure 1).

Table 2. Myocardial infarction cumulative incidence and mortality rates per 100,000 men by age and diagnostic categories. Aggregated data from 1997 to 1998 in the seven regions of the IBERICA Study (Spain)

\begin{tabular}{|c|c|c|c|c|c|}
\hline \multirow[b]{2}{*}{ Age } & \multirow[b]{2}{*}{ Population } & \multicolumn{2}{|c|}{$\begin{array}{l}\mathrm{NF} 1+\mathrm{F} 1+\mathrm{F} 2 \\
\text { Annual rate per } 100,000 \text { inhabitants }\end{array}$} & \multicolumn{2}{|c|}{$\begin{array}{l}\mathrm{NF} 1+\mathrm{F} 1+\mathrm{F} 2+\mathrm{F} 9 \\
\text { Annual rate per } 100,000 \text { inhabitants }\end{array}$} \\
\hline & & $\begin{array}{l}\text { Cumulative incidence } \\
\qquad(\mathrm{N}=7649)\end{array}$ & $\begin{array}{l}\text { Mortality } \\
(\mathrm{N}=2347)\end{array}$ & $\begin{array}{l}\text { Cumulative incidence } \\
\qquad(\mathrm{N}=8412)\end{array}$ & $\begin{array}{l}\text { Mortality } \\
(\mathrm{N}=3110)\end{array}$ \\
\hline $25-34$ & 986,992 & 9 & 2 & 9 & 2 \\
\hline $55-64$ & 581,897 & 365 & 102 & 398 & 135 \\
\hline $65-74$ & 508,300 & 678 & 264 & 762 & 348 \\
\hline $25-74^{\mathrm{a}}$ & $3,638,940$ & 210 & 64 & 231 & 85 \\
\hline $25-74^{\mathrm{b}}$ & $3,638,940$ & $189(184-193)$ & $55(53-57)$ & $207(202-211)$ & $73(70-76)$ \\
\hline $35-64^{b}$ & $2,143,648$ & $191(185-197)$ & $46(43-48)$ & $206(200-212)$ & $61(57-64)$ \\
\hline
\end{tabular}

F1: NF1: Fatal and non-fatal definite myocardial infarction.

F2: Fatal possible myocardial infarction.

F9: Fatal insufficient data.

${ }^{\text {a }}$ Crude rate.

${ }^{\mathrm{b}}$ Age-standardized rate using world population weights. Rate (95\% confidence interval).

$\mathrm{N}$ : Number of cases

Table 3. Myocardial infarction cumulative incidence and mortality rates per 100,000 women by age and diagnostic categories. Aggregated data from 1997 to 1998 in the seven regions of the IBERICA Study (Spain)

\begin{tabular}{|c|c|c|c|c|c|}
\hline Age & Population & \multicolumn{2}{|c|}{$\begin{array}{l}\mathrm{NF} 1+\mathrm{F} 1+\mathrm{F} 2 \\
\text { Annual rate per } 100,000 \text { inhabitants }\end{array}$} & \multicolumn{2}{|c|}{$\begin{array}{l}\mathrm{NF} 1+\mathrm{F} 1+\mathrm{F} 2+\mathrm{F} 9 \\
\text { Annual rate per } 100,000 \text { inhabitants }\end{array}$} \\
\hline $25-34$ & 958,214 & 1 & 0 & 1 & 0 \\
\hline $45-54$ & 709,940 & 19 & 4 & 22 & 6 \\
\hline $55-64$ & 612,337 & 74 & 25 & 84 & 35 \\
\hline $65-74$ & 598,855 & 215 & 84 & 251 & 120 \\
\hline $25-74^{\mathrm{a}}$ & $3,725,742$ & 52 & 19 & 60 & 27 \\
\hline $25-74^{\mathrm{b}}$ & $3,725,742$ & $39(38-41)$ & $13(12-15)$ & $45(44-47)$ & $20(18-21)$ \\
\hline $35-64^{\mathrm{b}}$ & $2,168,673$ & $28(26-31)$ & $8(7-9)$ & $32(30-35)$ & $12(11-13)$ \\
\hline
\end{tabular}

F1: NF1: Fatal and non-fatal definite myocardial infarction.

F2: Fatal possible myocardial infarction.

F9: Fatal insufficient data.

${ }^{\text {a }}$ Crude rate.

${ }^{\mathrm{b}}$ Age-standardized rate using world population weights. Rate (95\% confidence interval).

$\mathrm{N}$ : Number of cases 


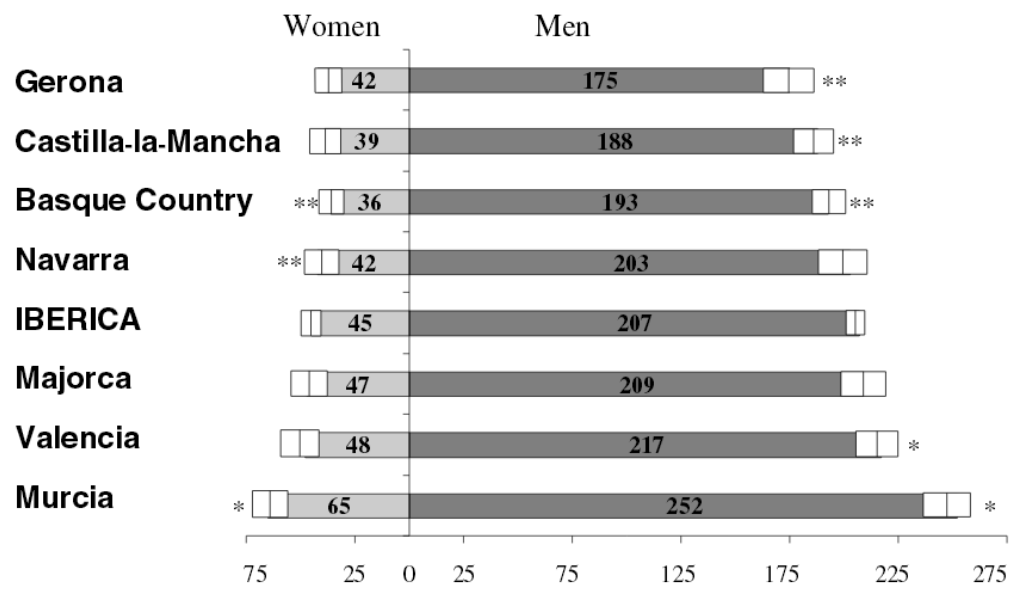

Figure 1. Myocardial infarction age-standardized cumulative incidence annual rate per 100,000 inhabitants in seven regions of Spain, 1997-1998, in patients aged 25-74 in the IBERICA Study. Fatal and non-fatal definite, fatal possible and fatal insufficient data myocardial infarction cases alone are presented. * Standardized cumulative incidence rate significantly higher than the IBERICA average. ** Standardized cumulative incidence ratio significantly lower than the IBERICA average. $\square$ (95\% Confidence interval.

Age-standardized mortality annual rates per 100,000 inhabitants for the 25-74 years population were 73 and 20 in men and women, respectively, and are presented by age groups, for all definite and fatal possible MI alone, and with the fatal insufficient data category in Tables 2 and 3. Age-standardized mortality rates for the 25-74 years population are presented by sex and region in Figure 2. Two regions had standardized mortality ratios significantly over the IBERICA average, and four regions had ratios under the average in men (Figure 2). These figures were two and one, respectively in women.

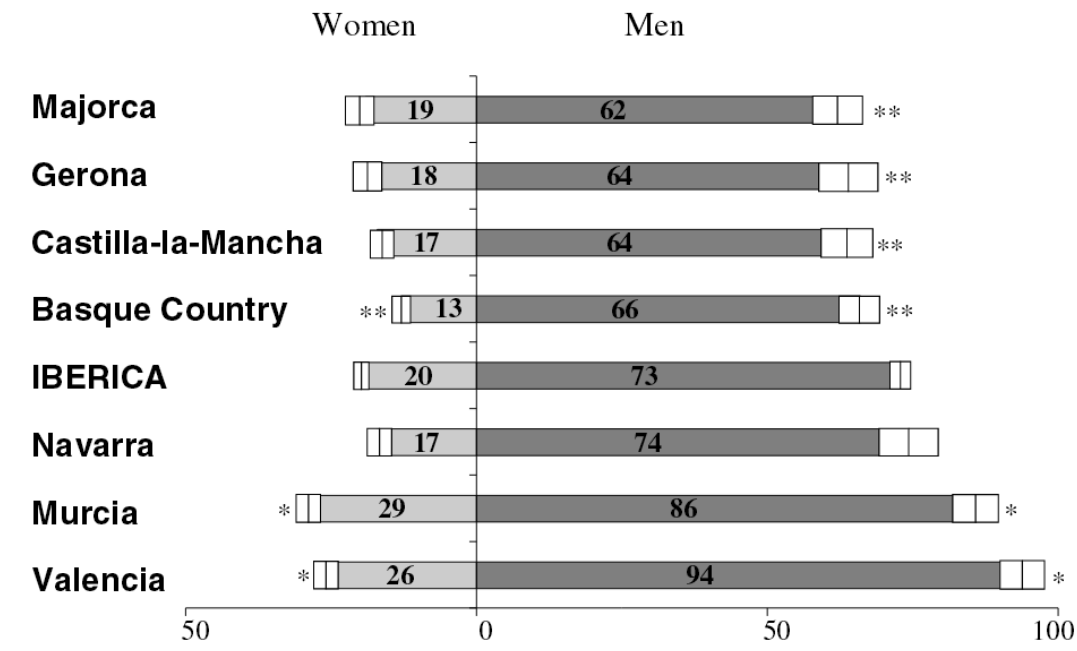

Figure 2. Myocardial infarction age-standardized mortality annual rate per 100,000 inhabitants in seven regions of Spain, 19971998, in patients aged 25-74 in the IBERICA Study. Fatal and non-fatal definite, fatal possible and fatal insufficient data myocardial infarction cases alone are presented. * Standardized mortality rate significantly higher than the IBERICA average. ** Standardized mortality ratio significantly lower than the IBERICA average. $\square$ q95\% Confidence interval 
The number of autopsies was 633 (19.0\% of all fatal cases). Crude case-fatality was $30.7 \%$ (2347/7649) in men aged 25-74 years and 35.6\% (691/1943) in women for all definite and fatal possible MI. With the fatal insufficient data category added the figures were 37.0 and $41.4 \%$, respectively. Agestandardized case-fatality was 31.4 and $24.2 \%$ in men aged 25-74 and 35-64 years, respectively, and 32.7 and $27.0 \%$, respectively, in women. These figures increased to 37.7 and $29.7 \%$, and to 44.2 and $35.6 \%$, respectively, the fatal insufficient data category was added.

\section{Discussion}

The present study shows the seven regions of Spain analyzed to be areas with low MI cumulative incidence and mortality rates close to those of other southern Europe Mediterranean countries, and much lower than the average WHO-MONICA study (see a comparison of selected world regions in Figure 3). This fact is noteworthy, since cardiovascular risk factors prevalence in Spain is relatively high [11-14]. The possible explanations for this apparent paradox may be related to differing environmental factors (i.e. physical activity and antioxidant-rich diet) and their interaction with genetic characteristics of the population [10]. Nonetheless, the proportion of mortality due to ischaemic heart disease was $12.1 \%$ in men (the main individual cause of death) and 10.2\% in women (third individual cause of death), in Spain in 1997-1998 [1]. Ischaemic heart diseases will have claimed more than 39,000 lives in year 2002 in Spain [18].

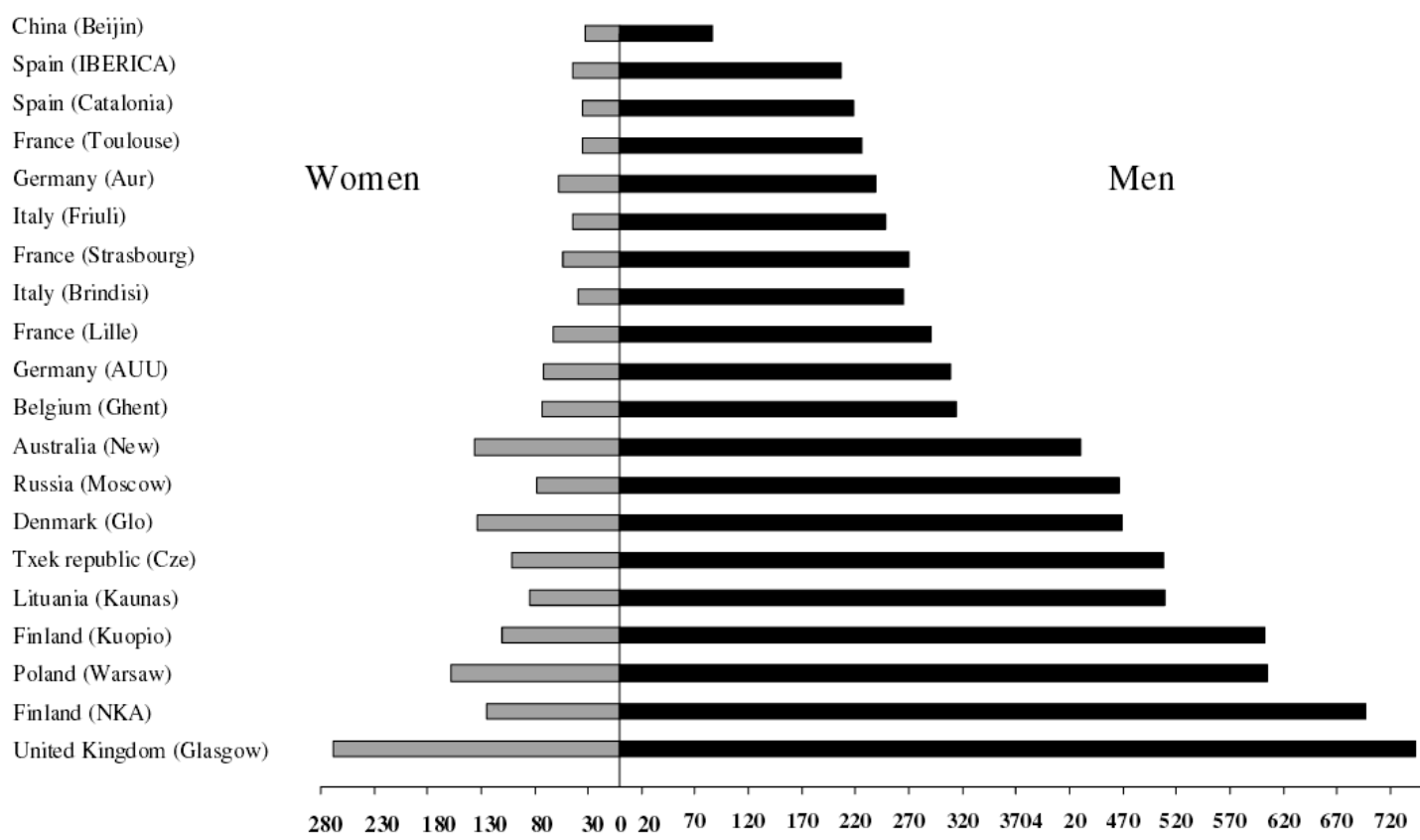

Figure 3. Age-standardized cumulative annual event rate by sex including fatal and non-fatal definite, fatal possible and fatal insufficient data myocardial infarction cases in a selection of regions participating in the WHO-MONICA study (aggregated data from 1984 to 1995) and in the seven regions of the IBERICA Study, Spain (aggregated data from 1997 to 1998). Based on reference number 4

The large variability in MI event rates within a low MI incidence area indicate that whatever the environmental risk (and protective) factors and their interaction with genetic characteristics vary at many levels, which provides interesting opportunities for investigating which factors may play a role in protecting population from coronary heart diseases. In particular, the effect of high levels of cholesterol may not have the same 25-year cardiovascular risk implications in Mediterranean countries of southern Europe as in the United States and central or northern Europe [19]. There are data indicating that cholesterol levels may have been high for as long as 25 years in Spain without producing the expected increase in the number of coronary events [20]. The modulation of cholesterol levels may be sensitive to 
other diet factors such as antioxidants, and to life-style characteristics such as physical activity which are frequent in Spain, and may counteract the effect of the high prevalence of cardiovascular risk factors [10].

Population 28-day case fatality was higher not only than that described in MI clinical trials (due to non-inclusion of patients who die before reaching hospital in the latter), but also than that of hospitalized MI patients [15]. Furthermore, our registry showed that 28-day case-fatality increased approximately by $25 \%$ when the 65-74 years decade was considered. Out-of-hospital deaths constitute more than two thirds of the 28-day overall case-fatality.

In our study, the age range was 25-74 years although the usual range in many studies is 35-64 years [21]. At least seven MONICA centers widened their registries to cover this range [5, 22, 23]. Comparability with other registries is, however, ensured by appropriate standardization of age groups 3564 years.

\section{Study characteristics}

One limitation, shared by all MI registries, arises when a MI patient fails to contact at least one of the sources of information periodically checked [10]. This is unlikely to occur [7]. Other limitations of this type of registries regard missing silent MI cases and failure to identify MI misdiagnosed as other pathologies. The frequency of the former has been estimated to be around $30 \%$ of all MI occurred in the Framingham cohort [24]. The latter was assessed in an analysis of 395 death certificates investigated in one of the participant areas [25]. I was concluded that investigating death certificates with 410-414 ICD 9th revision codes provided a specific criterion which failed to identify only $0.3 \%$ of definite and $3 \%$ of possible cases as compared with an extended revision of death certificates with other codes (i.e. diabetes mellitus, heart failure, hypertensive heart disease, hypertension and arrhythmia). In our study ECG was not coded with Minnesota code owing to the complexity of obtaining satisfactory standardization: thus, specially trained non-cardiologist physicians assessed ECGs.

Results have been presented in two groups of MI categories: fatal and non-fatal definite and fatal possible, and these categories plus dead patients with insufficient data. Figures obtained by the latter represent the most adverse situation if all insufficient data cases were in fact MI patients [25]. Only 3-6\% of such episodes are given a diagnosis other than MI when evaluated at necropsy [14]. On the other hand, the low number of autopsies (19.0\% of all fatal cases) led to a greater proportion of possible MI cases. Fatal cases classified as insufficient data in the MONICA project represented $22.9 \%$ of the whole [4], a figure similar to ours $(23.6 \%)$. The MONICA possible category in the present study was counted when assigned to fatal cases only. The 242 cases of non-fatal possible events in our study correspond to a clinical diagnosis of non-Q-wave MI or unstable angina cases in whom incomplete or non-specific cardiac enzyme curves were found along with a probable or ischaemic ECG. These patients were in consequence not included in the analysis. There is a high variability in the proportion of patients with non-Q wave MI in clinical series which is likely to be related to the fuzzy limit between non-Q wave MI and unstable angina. Neither these, nor other MONICA non-fatal possible cases were included in rate calculation since the vast majority of the latter usually correspond to unstable or other forms of angina patients and their inclusion would produce a difficult-to-interpret overestimation of rates. In fact, the inclusion of this category yields increases in rates that vary greatly among areas [7, 26]. Other more sensitive categorization strategies derived from WHO-MONICA algorithm [27] yield higher rates but it is likely that specificity then drops owing to inclusion of a number of unstable angina patients as MI.

Another important characteristic of the study is that we used the classical definition of MI according to the MONICA algorithm [16] since the new MI definition was not published at the time the study was carried out [28].

\section{Conclusion}

Our results confirm that cumulative incidence and mortality rates from MI in Spain are among the lowest in the industrialized world, although there is a substantial variability in event rates among regions in Spain: regions with the highest rates have approximately $50 \%$ higher rates than the regions with the lowest rates. 
- The myocardial infarction rates in Spain are among the lowest of the industrialized world,

- there is a substantial variability in event rates among regions,

- the variability among Spanish regions is lower than that found in international comparisons.

\section{Acknowledgements}

This study was funded by a research grant from AstraZéneca, grants from the Fondo de Investigación Sanitaria \# FIS 96/0026-01 to 05, FIS 97/1270 and FIS 98/1535, and by the Health care Administration of the following Spanish Autonomous Governments: Majorca, Castilla-La Mancha, Cataluña (CIRIT/2001 SGR 00408), Murcia, Navarra, Basque Country and Valencia. The authors also appreciate the field work from Villar L, Constela D, García A, Piñera P, Llamas C, Calvo AM y Aragón A, Marco R. They also grateful to Christine O'Hara for the English revision.

\section{Appendix 1}

\section{IBERICA Study Investigators:}

IBERICA-Basque Country: Elena Aldasoro (PI); Eva Alonso; Fernando Arós; José Ma Arteagoitia (PI); Covadonga Audicana; Mikel Basterretxea; Eduardo Castillo $(\dagger)$ Santiago Esnaola; Miguel A García Calabuig; Iraida Hurtado de Saracho; Miren Josebe Laresgoiti; Nerea Larrañaga; María José Lasa; Iñaki Lecuona; Nerea Muniozguren; Mª CresTobalina; JesúsMª San Vicente; Emilio Sanz.

IBERICA-Murcia: Lluís Cirera; JoséGarcía; Carmen Navarro; $\mathrm{M}^{\mathrm{a}}$ José Tormo (PI); Consuelo Martínez; Josefa Contreras; Fuensanta Aliaga; José $\mathrm{M}^{\mathrm{a}}$ Alonso; Manuel Belda; Rafael Bañón; JoséAntonio Castaño; Antonio Castilla; Juan Manuel Chiner; José $\mathrm{M}^{\mathrm{a}}$ Clemente; Amparo Egea; Francisco Felices; Manuel Fuentes; José Galcerá; Arcadio García; Francisco García; Pedro García; Gurmesindo González; Faustino Herrero; Pedro Jara; José Antonio Melgarejo; José Muñoz; Silvestre Nicolás; Juan Ortega; Miguel de Paco; Emilio Pérez; Pascual Rodríguez; Francisco Javier Rodríguez; Julio Ródenas; Francisco Ruiz-Martínez; José Antonio Ruiz; Fernando de San Eustaquio; Josefa Segura; José Antonio Serrano; Gines Torres; Luis Carlos Torres; Juan Vidal; Manuel Villegas.

IBERICA-Valencia: Amparo Albiñana; Carlos Antón; Joaquín Arguedas; Santiago Borrás; Susana Bosch; Adolfo Cabadés (PI); José P Calabuig; Enrique Castellanos; Javier Cebrián; Francisco J Domingo; Ildefonso Echánove; Enrique Ferrer; Mercedes Francés; Eva Gómez; Julián González; José Gregori; Javier Haba; Antonio López; Vicente López; Inmaculada Melchor; Rafael Montero; Julio Montes; Ramón Navarro; Manuel Palanca; Miguel Palencia; Miguel Pérez; Paula Ramírez; Juan Antonio Rodríguez; Manuel Roig; Javier Ruiz; Antonio Salvador; José Sotillo; Francisco Valls; Hermelinda Vanaclocha (PI); José Antonio Velasco; Oscar Zurriaga.

IBERICA-Castilla-La Mancha: Centro Coordinador: Antonio Segura (PI); Gema Vega (PI); Gema Rius. Investigadores colaboradores: Enrique Almar; Miguel Artigao; Esther Bermejo; Carmen García; Francisco García; Pedro Antonio Jiménez; Javier Lucas; Antonio Mateos; Amalia Navarro; Angel Puras; José María García.

IBERICA-Majorca: José Ingacio Ayestarán; Jaime Bergadá; Armando Bethencourt; Silvia Carretero; Magdalena Esteva; Miguel Fiol (PI); Catalina Forteza; José Francisco Forteza; Pedro Ibáñez; Josu López; Antonio Nicolau; Jon Pérez; María Riera; Antonio Rodríguez; Ana Rotger; Catalina Rubert; Joan Soler; Enrique Sospedra; Francisca Vara; Bernardo Vidal.

IBERICA-Navarra: Eduardo Alegría; Raquel Ancin; Enrique los Arcos; José Ramón Carmona; Vega García (PI); Conchi Moreno (PI); Teresa Rubio; Rafael Tejeira; Eugenio Torrano; Javier Turumbay.

IBERICA-Gerona: Antoni Agustí; Xavier Albert; Mariona Barcons; Francina Bassó; Josep Bisbe; Mariona Cardona; Núria Constans; Pere Cortés; Ma Isabel Covas; Roberto Elosua; Miguel Gil; Josep Carles Guerra; Rafel Masiá; Jaume Marrugat (PI); Silvia Martín; Carles Martínez; Angels Masabeu; M ${ }^{\mathrm{a}}$ Rita Massa; Francisco Monzón; Araceli Pena; Gloria Pérez; Carles Ponsatí; Isabel Ramió; Pere Roset; Izabella Rohlfs; Júlia Roura; Montserrat Sagué; Joan Sala (PI); Mariano Sentí; Joan Vila.

IBERICA-A Coruña: Antonio Amaro; Eugenia Ameneiros; Sara Cerdeira; Teresa Eguileta (†) Jorge Hervada; Alejandro Mesías; Javier Muñiz (PI); Pedro Rigueiro; Enrique Sáez; Jorge Salgado; Nicolás Vázquez; Luciano Vidán Martínez.

IBERICA- Coordinating centre: Jaume Marrugat; Roberto Elosua. 


\section{References}

1. Llácer A, Fernández-Cuenca R, Martínez de Aragón MV. Mortalidad en España en 1998. Evolución en la década 1989-1998. I. Mortalidad general,principales causas de muerte y de años potenciales de vida perdidos. Boletín Epidemiológico Semanal 2001; 9: 241-244.

2. Villar Alvarez F, Banegas Banegas JR. Objetivo 9. Reducir las enfermedades cardiovasculares. In: Alvarez Dardet A, Peiró S (eds), Informe SESPAS 2000. La Salud Pública ante los desafíos de un nuevo siglo. Granada: Escuela Andaluza de Salud Pública, 2000: 152 pp.

3. Murray CL, López A. Alternative projections of mortality and disability by cause 1990-2020: global burden of disease study. Lancet 1997; 349: 1498-1504.

4. Tunstall-Pedoe H, Kuulasma K, Mähönen M, Tolonen H, Ruokokoski E, Amouyel P. For the WHO MONICA Project.Contribution of trends in survival and coronary-event rates to changes in coronary heart disease mortality: 10-year results from 37 WHO MONICA Project populations. Lancet 1999; 353: 1547-1557.

5. Pérez G, Pena A, Sala J, Roset P, Masiá R, Marrugat J, IBERICA Investigators. Acute myocardial infarction case fatality, incidence and mortality rates in a population registry in the province of Spain 1990 to 1992. Int J Epidemiol 1998; 27: 599-604.

6. Hammar N, Ahlbom A, Theorell T. Geographical differences in myocardial infarction incidence in eight Swedish counties, 1976-1981. Epidemiology 1993; 3: 348-355.

7. Cambou JP, Genes N, Vaur L, Renault M, Etienne S, Ferrieres J, Danchin N. [Epidemiologie de l'infarctus du myocarde en France. Spécificités regionales.] Arch Mal Coeur Vaiss 1997; 90: 1511-1519.

8. Marrugat J, Sentí M. High cholesterol may not have same effect on cardiovascular risk in southern Europe as elsewhere. Br Med J 2000; 320: 249.

9. Artaud-Wild SM, Connor SL, Sexton G, Connor WE. Differences in coronary mortality can be explained by differences in cholesterol and saturated fat intakes in 40 countries but not in France and Finland. Circulation 1993; 88: 2771-2779.

10. Marrugat J, Masiá R, Elosua R, Covas MI. Cardiovascular protective factors: Can they explain for differences in mortality and morbidity between the Mediterranea and the Anglo-saxon population? Cardiovascular Risk Factors 1998; 9: 196-204.

11. Masiá R, Pena A, Marrugat J, Sala J, Vila JS, Pavesi M, Covas MI, Aubó C, Elosua R, IBERICA Investigators High prevalence of cardiovascular risk factors in Spain, a province with low myocardial infarction incidence. J Epidemiol Commun Health 1998; 52: 707-715.

12. Tormo Díaz MJ, Navarro Sánchez C, Chirlaque López MD, Pérez Flores D. Factores de riesgo cardiovascular en la región de Murcia. Rev Esp Salud Publica 1997; 71: 515-529.

13. Segura Fragoso A, Rius Mery G. Factores de riesgo cardiovascular en una población rural de Castilla-la Mancha. Rev Esp Cardiol 1999; 52: 577-588.

14. Banegas JR, Villar F, Pérez C, Jimenez R, Gil E, Muñiz J, Juane R. Estudio epidemiológico de los factores de riesgo cardiovascular en la población española de 35 a 64 años. Rev San Hig Pub 1993; 67: 419-445.

15. Proyecciones y Estimaciones Intercensales de Población. Instituto Nacional de Estadística. (Cited 15 July 2002) [1 Screen]. Available from: http://www.ine.es/inebase/cgi/um.

16. WHO MONICA Project. MONICA Manual. Part IV: Event registration. Section 1: Coronary event registration data component. (March 1999). Available from: URL: http://www.ktl.fi/publications/monica/manual/part4/iv1.htm, URN:NBN: fi-fe19981154.

17. Quality Assessment of Coronary Event Registration Data in the WHO MONICA Project (Cited 2002 July 10). [1 screen]. Available from URL: http://www.ktl.fi/publications/monica/coreqa/coreqa.htm.

18. Marrugat J, Elosua R, Martí H. Epidemiologíadela cardiopatía isquémica en España: estimación del número de casos y de las tendencias entre 1997 y 2005 . Rev Esp Cardiol 2002; 55: 337-346.

19. Kromhout D. On the waves of the seven countries study. Eur Heart J 1999; 20: 796-802.

20. Tomas-Abadal L, Varas-Lorenzo C, Bernades-Bernat E, Balaguer-Vintro I. Coronary risk factors and a 20-year incidence of coronary heart disease and mortality in a Mediterranean industrial population. The Manresa Study, Spain. Eur Heart J 1994; 15: 1028-1036.

21. Löwel H, Lewis M, Hörmann A, et al. Morbidity and mortality of myocardial infarction in the Augsburg MONICA study area in 1985-1987. Rev Epidem Santé Publ 1990; 38: 411-417.

22. Löwel H, Lewis M, Hörmann A, Keil U. Case finding, data quality aspects and comparability of myocardial infarction registers: Results of a south German register study. J Clin Epidemiol 1991; 44: 249-260.

23. Anonymous. [Tendències de la malaltia coronària a Catalunya, 1985-97: projecte MONICA.] Butlleti Epidemiológic de Catalunya 2000; XXI: 1-6.

24. Tuomilehto J, Arstila M, Kaarsalo E, Kankaanpaa J, Ketonen M, Kuulasmaa K, Lehto S, Miettinen H, Mustaniemi H, Palomaki P, et al. Acute myocardial infarction (AMI) in Finland-baseline data from the FINMONICA AMI register in 1983-1985. Eur Heart J 1992; 13: 577-587; Published erratum appears in Eur Heart J 1992; 13: 1153

25. García J, Cirera L, Tormo MJ, Martínez C, Contreras J, Navarro C. Utilidad del boletín estadístico de defunción para la identificación de muertes ext-rahospitalarias en un registro poblacional de infartos agudos de miocardio. Rev Esp Cardiol 2001; 54: 1041-1047.

26. Kannel WB. Silent myocardial ischemia and infarction: insights from the Framingham Study. Cardiol Clin 1986; 4: 583-591.

27. Martin CA, Hobbs MS, Armstrong B K. Measuring the incidence of acute myocardial infarction: the problem of possible acute myocardial infarction. Acta Med Scand 1988; 728 (Suppl): 40s-47s 
28. Myocardial infarction redefined-a consensus document of the joint European Society of Cardiology/ American College of Cardiology Committee for the redefinition of myocardial infarction. Eur Heart J 2000; 21: 1502-1513. 